\title{
NIETZSCHE, FREUD Y KOMAR \\ El fundamento antropológico de la terapia
}

\author{
Prof. Francisco Orioli
}

\section{Introducción}

La verdad como vigencia $y$ dinamismo (1978) es el título que lleva la desgrabación hecha por Ángel Velay de un seminario de Emilio Komar con el mismo nombre. Estructurado como un comentario al texto Verdad y unidad en la cura analítica (1960) de Charles Nodet, tiene como punto central la cuestión de la verdad, aplicada extensamente a su dimensión clínica sin relegar sus aspectos éticos y pedagógicos. La razón de la existencia de estos tres matices radica en que la verdad no es algo contingente, propio de una parte del hombre, sino que por el contrario apunta al centro de su ser y lo interpela directamente.

Este trabajo tiene por objetivo resumir y sistematizar el trasfondo filosófico de la obra de Komar, a la vez que pretende comparar esta obra con la antropología nietzscheana, base de la terapéutica de Sigmund Freud.

\section{La antropología de Nietzsche y \\ Freud}

El esquema antropológico de Friedrich Nietzsche (1844-1900), influido por Arthur Schopenhauer (1788-1860), supone la existencia de dos principios constitutivos y contradictorios entre sí. Uno, el apolíneo, es amante de la forma clara y esplendorosa, y tiende a la perfección estática, al mundo ideal. El segundo, bautizado con el nombre de dionisíaco, es inquietud desbordante y embriagadora, mueve a la danza y empuja a la vida (Leocata, 1979, p. 100). De la lucha y combinación de estos dos elementos constitutivos se conforma la realidad del hombre donde lo irracional (el principio dionisíaco) es motor y razón de ser de lo racional (el principio apolíneo) que de alguna manera limita el goce del desenfreno dionisíaco.

En materia fenoménica, el impulso apolíneo se evidencia en la creencia en un mundo objetivamente 
dado, amante de la forma y de los valores objetivos. La muerte de Dios, esto es la muerte de todo orden objetivo, inaugura el cauce libre del impulso vital, haciendo del hombre el constructor de nuevos valores y realidades. Por influencia de Schopenhauer, Nietzsche señala que en el hombre hay una voluntad profunda de poder, es decir, de aplastar a los otros y erigirse sobre ellos.

Según Nietzsche, el cristianismo ha ofrecido una moral de resentimiento, trastocando los valores del dominio y del poder (que serían los que realmente valen y dan vigor a la vida humana), por valores débiles y sin sentido como la compasión, la humildad, la bondad, etc.

Freud lee a Nietzsche (Freud, 2008, p. 437), mas no reconoce en otro momento su influencia. En él se puede ver la asunción de la voluntad de poder bajo la forma de pulsión de destrucción, al igual que el conflicto entre expresión de la vida y la represión, bajo la eterna lucha de las pulsiones de vida y de muerte.

En el vienés, el hombre se constituye en función de lo que sucede con las pulsiones mencionadas $^{1}$. Esto significa que las dimensiones más altas del hombre como son el arte, la filosofía y la religión derivan de pulsiones

1 Este esquema, denominado "pulsiónestructura" fue desarrollado ampliamente por Franz Alexander y parcialmente descartado por postfreudianos como Heinz Hartmann, Heinz Kohut y Jacques Lacan. instintivas en constante conflicto. Más aun, lo más característico de la persona como es su personalidad (aquello que la hace única e irrepetible, aunque en su constitución tenga elementos comunes a otros) es en realidad la máscara de un conflicto subyacente.

En este sentido, la cura como tal no existe, puesto que la guerra pulsional es constitutiva. Solo se puede hablar de éxito en el psicoanálisis con muchas reservas, y únicamente atendiendo a un lento progreso por el cual el Yo amplía muy poco su campo de libertad ${ }^{2}$. Campo que siempre se verá limitado o bien por exigencias pulsionales, o bien por demandas superyoicas (arraigadas, en parte, en el conflicto pulsional del cual no hay escapatoria) ${ }^{3}$.

\footnotetext{
${ }^{2}$ La utilización del concepto de libertad en psicoanálisis requiere una precisión, puesto que no se trata de una libertad connatural al ser humano asociada al bien, consiguiendo así realizarse cada vez más plenamente. Al contrario, lo que Freud entiende por libertad es más bien lo que en filosofía se denomina libertad de coacción, es decir, la liberación de agentes externos que coartan el ejercicio de la voluntad. Este malentendido surge de la influencia negativa de la moral kantiana de la época (véase nota 3 ).

3 Esta concepción por la cual la salud se asocia a cierto cese de mecanismos de represión y a la liberación de las pulsiones instintivas, es una contestación a la moral kantiana que tiene como eje el actuar por el deber mismo. Komar $(1978$, p. 9) señala muy lúcidamente que muchas veces la moral realista y católica es entendida como la ética kantiana del deber, por la que se le exige a la naturaleza humana algo externo a ella, igualando así el acto bueno a la represión y
} 


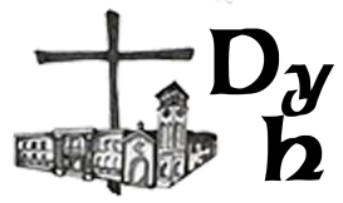

Cada persona es, de algún modo, un instante fugaz de la lucha de sus instintos, lo cual no da pie a concebir la singularidad humana como verdadera singularidad; es decir como un misterio con carácter de absoluto capaz, por su libertad, de autodeterminarse en función del bien que le ofrece la realidad. $\mathrm{O}$, lo que es similar, como un alguien que eligiendo el bien, madura y amplía su personalidad, enriqueciéndola y llevándola a formas más altas de realización ${ }^{4}$.

\section{La antropología de Emilio Komar}

El esquema aquí es bastante diferente. Inserto en una tradición de filosofía realista y cristiana, la propuesta de Komar no deja de ser innovadora y contrastante con las antropologías de fin del siglo XIX y $X X$.

Las diferencias radican especialmente en que Komar entiende al hombre con una especial consistencia ontológica. Es decir que la persona, en tanto que persona, es un absoluto que no es un agregado

el acto malo a la manifestación de los instintos. Sin embargo esta manera de entender la moral realista y católica es incorrecta puesto que la virtud no es una exigencia por fuera de la naturaleza, sino una exigencia de la naturaleza. El hombre siente la necesidad de ser justo más allá de cualquier imposición externa. La naturaleza exige su propia realización.

${ }^{4}$ Para un conocimiento más acabado de la antropología freudiana véase ROLDÁN, J. P. (2006) Consideraciones filosóficas sobre el amor a sí mismo en la obra de Freud. Revista de Psicología UCA, Vol 2 (4), p. 75-110. de otra cosa, sino que es y vale por sí misma. Esto se opone al pensamiento de Nietzsche y Freud que consideran que la persona es, a grandes rasgos, el derivado de un conflicto. Para el filósofo esloveno el ser personal precede al conflicto, lo cual cambia radicalmente la manera de concebir la terapéutica.

Como fue dicho anteriormente, el texto gira en torno a la importancia de la verdad en dos dimensiones esenciales: como dinamismo y como vigencia. Para explicar esta consideración, Komar señala que dinamismo significa que hay una tendencia, una voluntad que busca permanentemente la verdad. Que el hombre, por más que no quiera saber nada de la verdad, no puede sino buscarla $(1978$, p. 20). Es decir, que en el hombre siempre está esa inquietud por conocer la verdad, aunque él mismo crea que la verdad es algo relativo o construido por él. Quien considera que la verdad depende del punto de vista de cada uno, anhela con todo su ser que esa proposición sea absolutamente verdadera e independiente del parecer de los demás. Hay en el hombre una constante búsqueda por conocer lo que las cosas son y de actuar de acuerdo a ellas.

La otra faceta de la verdad es su vigencia, y por ello Komar sostiene que este carácter está unido íntimamente a la noción de sentido de la realidad. De allí que si no veo el sentido de las cosas, ni su valor, mi mente carecerá de alimento, no se desarrollará, no vivirá, y mi voluntad 
y mi afectividad no se sentirán estimuladas por la atracción de los valores (1978, p. 19). Se puede decir que esta dimensión apunta directamente al valor de las cosas en sí, al valor objetivo y trascendente del hombre. Este conocimiento de lo que las cosas realmente son, habla al hombre porque le exige una actitud, una respuesta. Esta dimensión quizás se vea más claramente en lo que concierne a las relaciones personales, constitutivas en el ser personal de cada uno. En este sentido, por ejemplo, para amar realmente a una persona es necesario el conocimiento real de esta ${ }^{5}$. Escapar al conocimiento de quién es el otro es escapar a la verdad, y escapar a la verdad es refugiarse en la propia ilusión. De allí que sea tan nocivo el apego a la ilusión en detrimento de la verdad que descansa en la realidad.

En la relación entre el dinamismo como persecución incansable por la verdad y la vigencia como su asiento en la realidad, la antropología de Komar se resuelve edificante para el ser humano. Desde aquí las consideraciones filosóficas parten hacia el pensamiento de la libertad del hombre como la cualidad de la voluntad humana para alcanzar el bien, aquello que es vigente para

\footnotetext{
5 Conocimiento real no significa conocimiento total. Al contrario, en tanto más real es el conocimiento de la otra persona más conciencia hay de que es un misterio, por lo que se abren nuevas dimensiones a explorar, dimensiones incapturables en su totalidad por el conocimiento humano.
}

él y en él y mediante lo cual se realiza. La libertad, en tanto característica fundamental del hombre, se relaciona con el desarrollo humano (es decir, el camino hacia la plenitud del ser) porque es gracias a ella que se puede abrazar la verdad, el bien y la belleza. Estas tres dimensiones de la realidad hacen al hombre más hombre puesto que si no vamos a la unidad, a la verdad, al ser, ese impulso primitivo fundamental [la voluntad de verdad], no llega a su objetivo (1978, p. 20).

Entre las tantas cosas que pueden conocerse, una brilla por su relevancia: el ser propio, la intimidad personal o, lo que diversos autores denominan el sí-mismo (Hartmann, Winnicott, Kohut, Kernberg). Komar señala la importancia del autoconocimiento apelando a dos principios griegos: Conócete a ti mismo y sé lo que eres (1978, p. 25) y sostiene que en la medida en que nos estamos conociendo como somos, tenemos que realizarnos (1978, p. 25). De allí que la terapia, fundamentada en la verdad como potencia transformadora para la vida humana sea definida más adelante como el des-mantelamiento detallado, perfecto, de unas construcciones de mentiras vitales para que las cosas vuelvan a su lugar y se produzca la sencillez que es el signo de la verdad (1978, p. 39). La cura analítica gira en torno al paciente en tanto persona $y$, por ende a su voluntad de verdad, a su necesidad de saber quién es para ser quien debe ser. La terapia, que por esto mismo marcha sobre una 


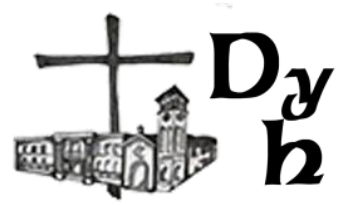

energía que no es la propia (1978, p. $13)$, es el ir corriendo, junto al enfermo, los pequeños y grandes engaños que no permiten un conocimiento pleno de uno mismo y, por lo tanto, la realización del propio ser según la configuración del universo personal. Salud, por lo tanto, será autorealización imposible de alcanzar si no está unida al conocimiento de la verdad.

\section{Conclusión}

Se han visto los puntos más importantes de la antropología nietzscheana y komariana con sus efectos en el ámbito terapéutico. A modo de resumen, podemos decir que la primera, signada por los aportes de Sigmund Freud, considera que: a) el conflicto es algo esencial al hombre, principalmente el conflicto pulsional; b) el hombre carece de consistencia ontológica, es decir, de un ser propio que lo muestra como un absoluto dotado de dignidad; c) no hay libertad como tal, puesto que el hombre vive preso de sus conflictos con la realidad y sus instancias psíquicas.

Por otra parte, la segunda antropología presentada considera que: a) el hombre tiene consistencia ontológica y, por lo tanto carácter de absoluto dotado de dignidad; b) en el hombre hay una voluntad natural por conocer la verdad y realizarse de acuerdo a ella; c) la libertad es constitutiva en el hombre $y$ es gracias a ella que el hombre puede alcanzar la plenitud de su persona; d) la verdad sobre sí mismo es la más importante en materia de desarrollo personal.

De allí que la primera antropología derive en una terapéutica enfocada en darle más libertad al Yo y cierto cauce libre a los impulsos. La segunda antropología deriva en una terapéutica abocada al conocimiento personal y a la realización del propio ser, atendiendo especialmente a la realidad de este sujeto frente a las exigencias universales de la naturaleza humana.

Esta obra de Komar es extensa, desde todo punto de vista. Su densidad y profundidad teórica se han vuelto, de alguna manera, inabarcables para este trabajo. Han quedado por fuera numerosos temas que hacen a la antropología y que merecen ser leídos para más aportes a una terapia centrada en la persona. Sus consideraciones son fundamentales para todo aquel que trabaja en el campo de la salud mental. Salud que es, en definitiva, realización ontológica y personal.

\section{Bibliografía}

Freud, S. (2008). Cartas a Wilhelm Fliess (1897-1904). Buenos Aires: Amorrortu.

Komar, E. (2006). La verdad como vigencia $y$ dinamismo. Buenos Aires: Ediciones Sabiduría Cristiana. 


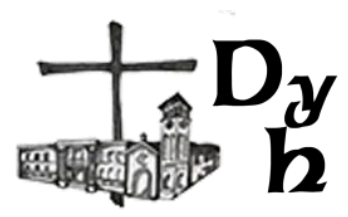

Leocata, F. (1979). Del Iluminismo a nuestros días. Boulogne: Ediciones Don Bosco Argentina. 